
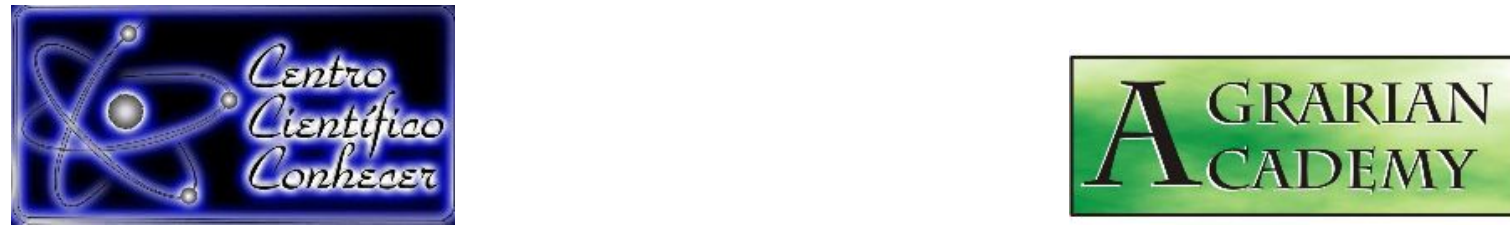

\title{
ACOMPANHAMENTO DA PRATICA DO BEM ESTAR ANIMAL NO MANEJO PRÉ- ABATE DE UM BOVINO SUBMETIDO AO ABATE DE EMERGENCIA: RELATO DE CASO
}

Laura Baialardi Galvão ${ }^{*}$, João Eudes Vargas Rezende ${ }^{2}$, Lyzandra Paulla de Castro Portilho $^{2}$, Natalia Holtz Alves Pedroso Mora ${ }^{3}$, Glaucenyra Cecília Pinheiro da Silva ${ }^{4}$

1- Bacharel em Medicina Veterinária, Mestranda do Programa de Biociência Animal da Universidade Federal de Jataí (laurinha_baialardi@hotmail.com)

2- Bacharel em Medicina Veterinária, Centro Universitário do Vale do Araguaia, Barra do Garças - MT/BRASIL

3- Zootecnista, Docente, Dra., Centro Universitário do Vale do Araguaia (UNIVAR), Barra do Garças - MT/BRASIL

4- Médica Veterinária, Pós-doutoranda na Universidade de Cuiabá (UNIC), Cuiabá - MT/BRASIL

Recebido em: 02/06/2019 - Aprovado em: 15/06/2019 - Publicado em: 22/07/2019 DOI: 10.18677/Agrarian_Academy_2019a2

O presente estudo teve por objetivo relatar o caso de um bovino no momento préabate enfatizando a importância da prática do bem-estar. Atualmente existe uma grande preocupação com 0 abate humanitário, que pode ser definido como um conjunto de procedimentos que garantem o bem-estar animal (BEA), ou seja, evitar que os animais passem por dor ou sofrimento desnecessários, e não estão apenas relacionadas ao aspecto moral e ético, mas também associadas a um impacto econômico, pois, bovinos estressados e maltratados geram carcaças de menor qualidade e com menor tempo de prateleira. Foi avaliado um animal da espécie bovina da raça Nelore, macho, não castrado, com aproximadamente 4 anos de idade, com aproximadamente $500 \mathrm{Kg}$ submetido à um abate de emergência, após o desembarque por ter sofrido um trauma na falange posterior direita, impossibilitando sua movimentação. Foi realizado o acompanhamento do bovino, desde o seu desembarque, até o destino final da carcaça. É necessário investir na qualificação de funcionário e melhora das instalações do frigorifico e transporte, permitindo assim identificar fatores que influenciam no bem-estar e na qualidade da carne, investigando nos perigos e amenizando os pontos críticos responsáveis pelos principais prejuízos, a fim de evitar estresse desnecessário ao animal.

PALAVRAS-CHAVE: Abate humanitário, bovinos, qualidade, sanidade. 


\title{
SIDE DISH OF ANIMAL WELFARE PRACTICE IN THE PRE-ABATE MANAGEMENT OF A BOVINE: CASE REPORT
}

\begin{abstract}
There is a great deal of concern today about the humanitarian slaughter, which can be defined as a set of procedures that ensure animal welfare, hat is, to prevent animals from suffering unnecessary pain or suffering, it is important to emphasize that the welfare and sanity requirements of the animal at the pre-slaughter moment that goes from the embarkation of the animals in the farm to the desensitization of the same ones, are not only related to the moral and ethical aspects, they are also associated with an economic impact, since stressed and mistreated cattle generate less quality carcasses with shorter shelf life. The present study aimed to report the case of a bovine at the time of slaughter emphasizing the importance of the practice of well-being.
\end{abstract}

KEYWORDS: Humanitarian slaughter, cattle, quality, health.

\section{INTRODUÇÃO}

O Brasil se destaca como grande produtor mundial de alimentos, sendo o agronegócio uma das bases de sua economia. A pecuária bovina brasileira é um dos segmentos mais importantes do setor agropecuário, já que possui o segundo maior rebanho comercial de bovinos do mundo, com cerca de 200 milhões de cabeças e faturamento de $R \$ 73,8$ bilhões no ano de 2015 (BRASIL, 2015).

A exigência por produtos de qualidade está cada vez maior, ressaltando a importância de uma maior responsabilidade com a produção sustentável e a promoção do bem-estar (tanto humano como animal), propiciando a satisfação do consumidor, fornecendo produtos nutritivos, saborosos e seguros. Além disso, assegurar a renda do produtor sem ocasionar prejuízos ao ambiente (ALVES et al., 2016).

O bem-estar animal, sempre teve grande atenção, quando relacionado ao abate de animais para a alimentação humana. A partir disso, houve uma crescente demanda por processos denominados abates humanitários, que podem ser definidos como o conjunto de procedimentos técnicos e científicos que garantem o bem-estar dos animais desde o embarque na propriedade rural até a operação da sangria no abatedouro e tem como objetivo de reduzir sofrimentos inúteis ao animal a ser abatido (ROÇA, 2003).

Atualmente a preocupação com o bem-estar, ou seja, com a forma como as espécies de produção estão sendo mantidas e o cuidado com os animais utilizados na produção de alimentos é fundamental, sendo assim, existe a necessidade de desenvolvimento de pesquisas que investiguem e avaliem os pontos críticos relacionados à produção bovina, visto que, estes influenciam no desempenho dos sistemas produtivos pecuários e na conquista de um produto final de maior qualidade (SILVA; BORGES, 2015).

O momento pré-abate dos animais deve ser executado da condição mais semelhante possível de suas características naturais, possibilitando equilíbrio e harmonia em seu habitat natural, visto que animais possuem emoções, sentimentos e preferências. $O$ ambiente deve oferecer espaços que possibilitem a movimentação, abrigo que forneça conforto térmico, água e alimentação de que obedeçam às suas necessidades fisiológicas. (KOKNAROGLU; AKUNAL, 2013).

O presente trabalho teve como objetivo, observar o panorama das condições de pré-abate de emergência de um bovino sendo associado aos diversos métodos 
de bem-estar animal no frigorifico, relatando o caso desde o transporte até a sangria, enfatizando os benefícios trazidos para os matadouros-frigoríficos pela adoção de técnicas de abate humanitário.

\section{RELATO DE CASO}

Em julho de 2016, em um frigorifico na cidade de Barra do Garças-MT um animal da espécie bovina da raça Nelore, macho, não castrado, com aproximadamente 4 anos de idade, com aproximadamente $500 \mathrm{Kg}$ foi submetido à um abate de emergência, após o desembarque por ter sofrido um trauma na falange posterior direita, impossibilitando a movimentação do animal. Foi realizado o acompanhamento do bovino, desde o seu desembarque, até o destino final da carcaça.

O animal foi submetido à anamnese onde apresentou parâmetros, cardíacos, respiratórios e temperatura corporal normais. Apresentava lesão no chifre direito (FIGURA 1), e temperatura corporal de $42^{\circ} \mathrm{C}$ em ambiente aberto recebendo incidência solar direta. $O$ frigorífico não forneceu uma condição térmica ideal para a espécie, afetando assim, na liberdade de estresse e desconforto, que estão entre as cinco liberdades do animal, na qual, são instrumentos reconhecidos mundialmente para diagnosticar a promoção do bem-estar animal.

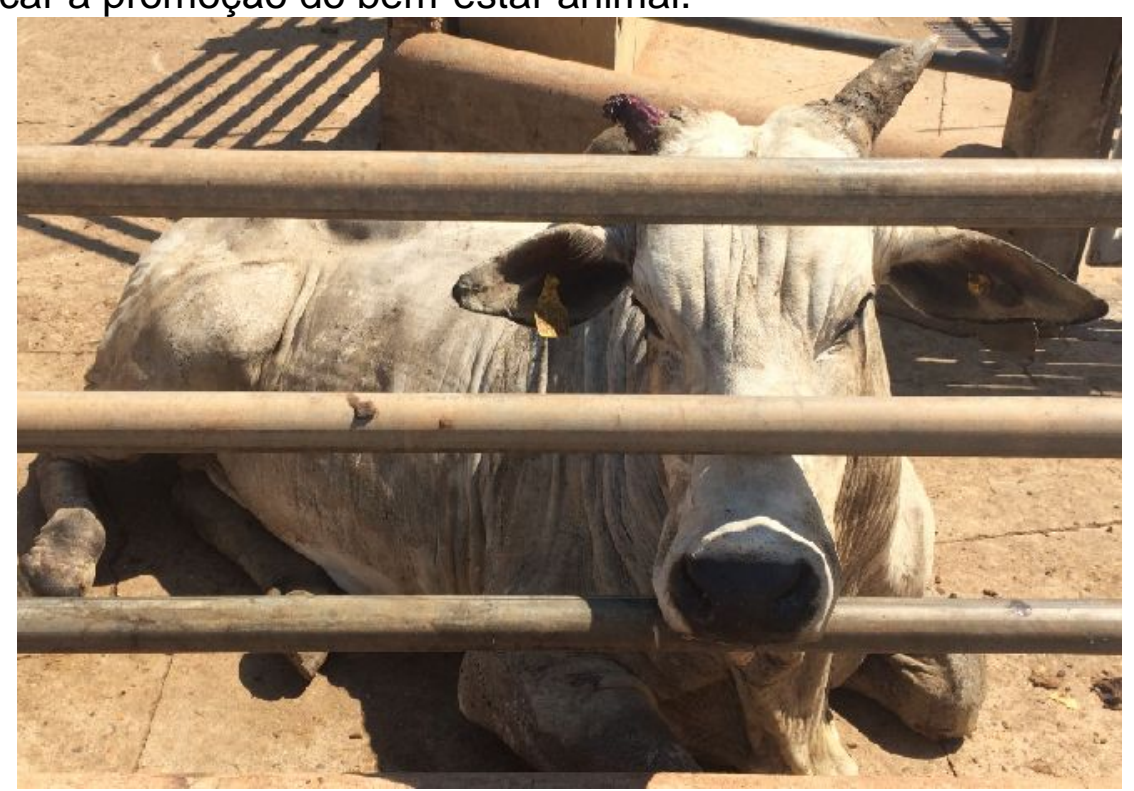

FIGURA 1- Bovino caído no corredor de desembarque com lesão no chifre direito (Arquivo pessoal, 2016).

Como o animal estava caído no corredor de desembarque, ocorreu pisoteio por outros bovinos que estavam descendo do caminhão, gerando assim hematomas pelo corpo. Foi realizado o abate de emergência a fim de assegurar o bem-estar desse animal e obter menos prejuízos econômicos no momento de abate.

$\mathrm{O}$ abate de emergência foi realizado por um funcionário treinado para esse tipo de situação, onde o animal foi contido, para facilitar a insensibilização, que foi realizada por uma pistola de dardo cativo portátil. Após a comprovação da insensibilização, o animal foi sangrado imediatamente, e por meio de um carrinho de transporte (FIGURA 2) foi encaminhado para sala de abate. 


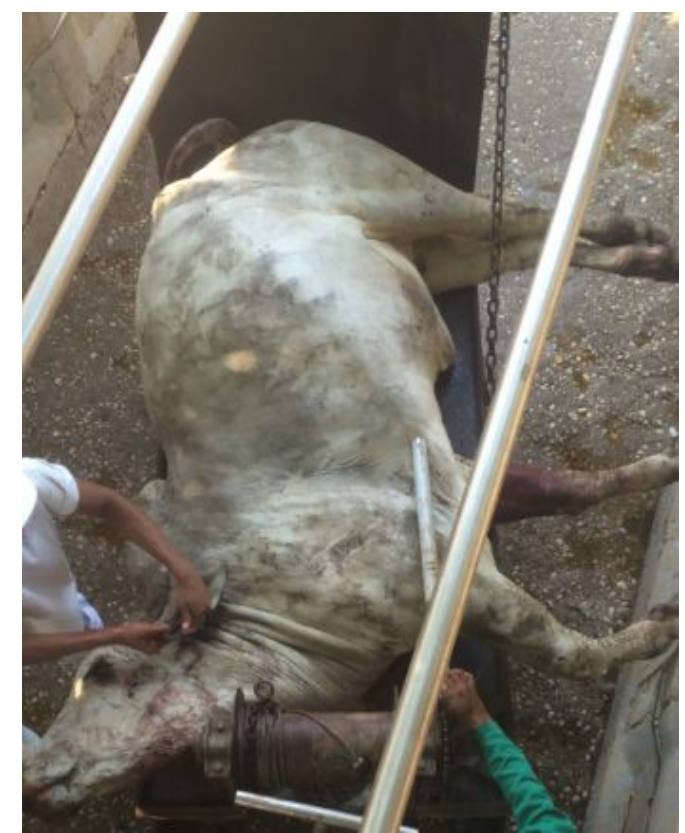

FIGURA 2- Bovino no carrinho de transporte (Arquivo pessoal, 2016).

Nas linhas de inspeções, as vísceras, patas, cabeça, estavam todas dentro do padrão de normalidade, sem condenação de nenhum órgão. Entretanto, a carcaça apresentou hematomas do tipo recente (FIGURA 3), mostrando evidências do momento que o animal foi pisoteado como também pode ser sugerido hematomas oriundos no transporte, causando assim uma perda econômica. Foi observado hematomas antigos principalmente no quarto traseiro do animal, provavelmente 0 animal foi acometido de um manejo errôneo na propriedade.

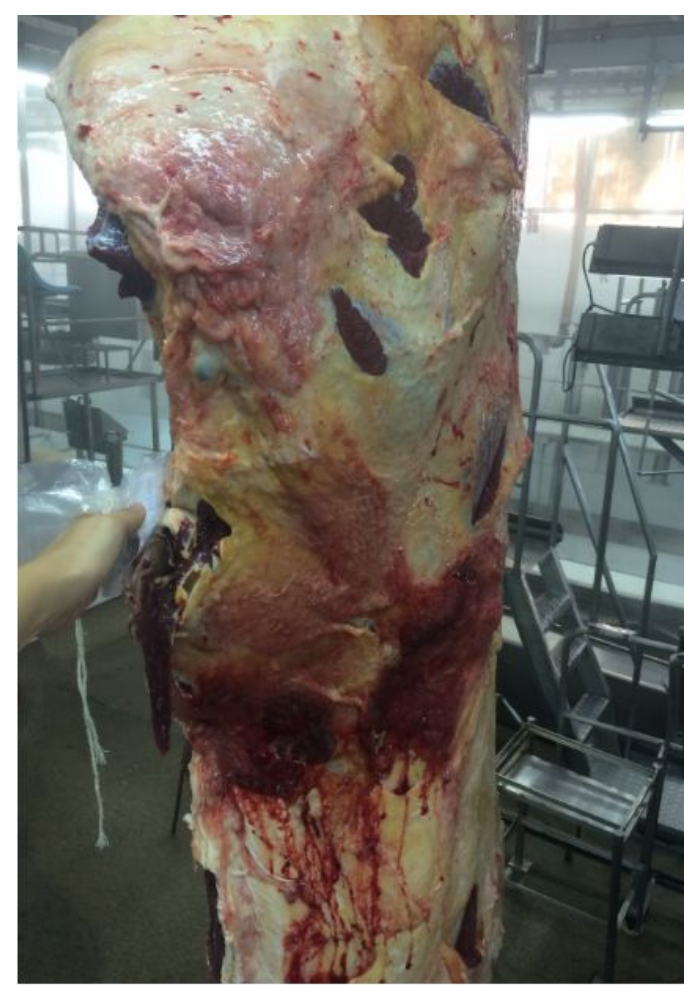

FIGURA 3 - Hematomas na carcaça do bovino abatido (Arquivo pessoal, 2016). 


\section{DISCUSSÃO}

Os abatedouros frigoríficos evoluíram nos últimos anos com introdução de novas tecnologias de equipamentos com objetivo de alcançar qualidade na produção junto com a promoção do bem-estar animal (CARLESCl et al., 2014). Durante o transporte até o abate no estabelecimento deve ser cumprido rigorosamente um protocolo de manejo, visando o conforto e proteção dos mesmos (BRASIL, 2017).

O manejo pré-abate é um período extremamente crítico e de longo estresse aos animais, sendo necessário desenvolver técnicas que tem como objetivo diminuir o estresse visando o conforto dos animais, caso contrário com um manejo agressivo e/ou inapropriado, resultará em sérios problemas de hematomas, contusões e fraturas. Nesse caso não há somente perdas na carcaça do animal, mas também prejuízos econômicos (ROÇA, 1999). Petroni et al. (2013) avaliaram lesões no quarto posterior de 133 animais abatidos, onde a perda total desses animais foi de $15,6 \mathrm{~kg}$, o que equivale em $177,3 \mathrm{~g}$ retiradas por animal. Considerando $R \$ 90,00$ por animal e a perda de $117,3 \mathrm{~g}$, o prejuízo por animal seria de $\mathrm{R} \$ 0,70$ ao pecuarista, apenas nas lesões presentes nesta região, o que aponta a necessidade de cuidados nesse momento.

Devido aos fatores mencionados, o abate humanitário, que pode ser definido como a soma de medidas de procedimentos técnicos que asseguram o bem-estar dos animais desde o embarque na propriedade rural até o momento da sua morte no frigorífico, vem sendo mundialmente utilizado. Quando não são executados conforme a legislação vigente, o abate pode ser apontado como maus-tratos (SANTOS-FILHO; MAYRINK, 2017). Em específico, o abate de emergência deve ser realizado o mais rápido possível. A insensibilização é realizada para promover o estado de inconsciência do animal, evitando assim estresse, medos, dor e sofrimento. A eficiência da insensibilização pode ser afetada por agravantes como falta de manutenção dos equipamentos, falta de mão-de-obra qualificada dos funcionários e estresse dos animais (SOBRAL et al., 2015).

As contusões e hematomas são as principais perdas para o frigorífico, e, são ocasionadas ainda no animal vivo (MENDONÇA; CAETANO, 2017), como observado nesse caso. A presença de hematomas é um indicativo de manejo inadequado, o qual pode ter ocorrido em qualquer etapa do processo pré-abate, além disso, a carne da região atingida pela contusão tem uma aparência feia e desagradável não sendo apta para o consumo humano, mais por um aspecto estético do que higiene e, durante a inspeção post-mortem, é submetida a um toalete intenso, podendo até ser desclassificada com prejuízo financeiro (STRAPPINI et al., 2009)

O manejo inadequado em diversas etapas, desde o embarque até a insensibilização, são um dos fatores de aspectos mais depreciativo das carcaças bovinas sendo uma das principais causas de condenação total (SILVA et al., 2016). Em um estudo realizado por Polizel Neto et al. (2015), o lombo foi o local mais afetado com $50,35 \%$ das lesões encontradas e o coxão com uma frequência de $36,38 \%$. Lembrando que os principais cortes comerciais no Brasil, como alcatra, picanha, maminha, coxão mole, contra filé, entre outros se encontram exatamente nos locais mais afetados desse estudo. Concordando com Civeira et al. (2006) que observaram que as estruturas mais acometidas, foram os quartos posteriores, seguido do vazio, lombo e costela. Segundo Roça (1999) o estresse crônico antes do abate, gerando exaustão física do animal, é o principal fator da carne seca, firme e escura (DFD) que consiste em uma carne com um $\mathrm{pH}$ alto em virtude das 
insuficientes reservas de glicogênio no momento do abate, apresentando valores superiores a 6,0 gerando aspecto indesejável.

\section{CONCLUSÃO}

O manejo pré-abate está diretamente relacionado com o bem-estar animal, qualidade da carne e prejuízo econômico. O cumprimento das questões de bemestar animal, além de resultar uma carne de melhor qualidade e promove um abate mais humanitário, mesmo de emergência. Portanto, é necessário investir na qualificação de funcionário e melhora das instalações do frigorifico e transporte, permitindo assim identificar fatores que influenciam no bem-estar e na qualidade da carne, investigando nos perigos e amenizando os pontos críticos responsáveis pelos principais prejuízos, a fim de evitar estresse desnecessário ao animal.

\section{REFERÊNCIAS}

ALVES, A.R.; JUNIOR-FIGUEIREDO, J.P.; SANTANA, M.H.M.; ANDRADE, M. V.M.; LIMA, J.B.A.; PINTO, L.S.; RIBEIRO, L.M. Efeito do estresse sobre a qualidade de produtos de origem animal. Pubvet, v. 10, n. 6, p. 448-459, 2016.

BRASIL. Decreto $n^{\circ}$ 9.013/2017 de março de 2017. Regulamento da Inspeção Industrial e Sanitária de Produtos de Origem Animal - RIISPOA - Ministério da Agricultura, Pecuária e Abastecimento e Desenvolvimento Rural. Disponível em: < http://www2.camara.leg.br/legin/fed/decret/2017/decreto-9013-29-marco-2017784536- publicacaooriginal-152253-pe.html>. Acesso em: 05 fevereiro 2019.

BRASIL, Ministério da Agricultura, Pecuária e Abastecimento - Bovinos e Bubalinos. $2015 \quad$ Disponível em: <http://www.agricultura.gov.br/animal/especies/bovinos-e-bubalinos >. Acesso em: 22 de maio de 2019. Fora da ordem alfabética.

CARLESCI, R.H.; BURGER, K.P.; ROSSI, G.A.M.; SABA, R.Z.; VIDAL-MARTINS, A.M.C.; GONZALEZ, P.O. Eficácia da insensibilização em bovinos pelo uso de pistola pneumática de penetração em matadouro-frigorífico no Estado de São Paulo, Brasil. Revista Brasileira de Higiene e Sanidade Animal, v. 8, n. 1, p.73-80, 2014. Disponível em: < http://dx.doi.org/10.5935/1981-2965.20140005> DOI: 10.5935/1981-2965.20140005.

CIVIEIRA, M.P.; RENNER, R.M.; RODRIGUES, N.C.; VARGAS, R.E.S. Avaliação do bem-estar animal em bovinos abatidos para consumo em frigorífico do Rio Grande do Sul. Veterinária em Foco, v. 4, n. 1, p. 5-11, 2006.

KOKNAROGLU, H.; AKUNAL, T. Animal welfare: An animal science approach. Meat Science, v. 95, n. 4, p. 821-827, 2013. Disponível em: <https://doi.org/10.1016/j.meatsci.2013.04.030>. DOI:10.1016/j.meatsci.2013.04.030.

MENDONÇA, P.M.; CAETANO, G.A.O Abate de bovinos: Considerações sobre o abate humanitário e jugulação cruenta. Revista Pubvet. v.11, n.12, p.1196-1209, 2017. Disponível em: <https://doi.org/10.22256/pubvet.v11n12.1196-1209> DOI: 10.22256/pubvet.v11n12.1196-1209. 
PETRONI, R.; BURGER, K.P.; GONÇALEZ, P.O.; ROSSI, G.A.M.; VIDAL-MARTINS, A. M. C.; AGUILAR, C. E. G. Ocorrência de contusões em carcaças bovinas em frigorífico. Revista Brasileira de Saúde e Produção Animal, v.14, n.3, 2013. Disponível em: < http://dx.doi.org/10.1590/S1519-99402013000300009>. DOI: 10.1590/S1519-99402013000300009.

POLIZEL N.; ZANCO, N.; LOLATTO, D.C.J.; MOREIRA, P.S.A.; DROMBOSKI, T. Perdas econômicas ocasionadas por lesões em carcaças de bovinos abatidos em matadouro-frigorífico do norte de Mato Grosso. Pesquisa Veterinária Brasileira. v. 35, n. 4, p. 324-328, 2015. Disponível em: < http://dx.doi.org/10.1590/S0100736X2015000400002>. DOI: 10.1590/S0100- 736X2015000400002.

ROÇA, R.O. Abate humanitário melhora a carne: bem-estar animal na hora do abate influencia na qualidade do produto. Revista Açougueiro \& Frigorifico, v.5, n. 42, 1999.

ROÇA, R.O. Bem-estar animal no Brasil: receita de primeiro mundo. Revista Carne. n. 320, 2003.

SANTOS FILHO, A.M.P.; MAYRINK, R.R. Medicina Veterinária Forense. In: Jesus Antonio Velho; Gustavo Caminoto Geiser; Alberi Espindula. (Org.). Ciências Forenses. Uma introdução às principais áreas da Criminalística Moderna. 1ed.Campinas: Millenium editora, p. 271-290, 2017.

SILVA, A.A. da.; BORGES, L.F.K. Considerações sobre o bem estar animal na produção de bovinos - Revisão Bibliográfica. Revista Ciência e Tecnologia, v. 1, n. 1, p. 1-8. 2015.

SILVA, V.L.; GROFF, A.M.; BASSANI, C.A.; PIANHO, C.R. Causas de condenação total de carcaças bovinas em um frigorífico do estado do Paraná. Relato de Caso. Revista Brasileira de Higiene e Sanidade Animal, v.10, n.4, p.730-741, 2016. Disponível em: <https://doi.org/10.5935/1981-2965.20160060> DOI: 10.5935/19812965.20160060.

SOBRAL, N.C., ANDRADE, E.N. \& ANTONUCCI, A.M. Métodos de insensibilização em bovinos de corte. Revista Científica de Medicina Veterinária, p. 251-10, 2015.

STRAPPINI, A.C.; METZ, J.H.M. GALLO, C.B.; KEMP, B. Origin and assessment of bruises in beef cattle at slaughter. Animal, v.3, p 728-736, 2009 